\title{
Do bone geometrical properties of the proximal femoral diaphysis reflect loading history, muscle properties or body dimensions?
}

Running title: Loading history, muscle properties and proximal femoral diaphysis

Sirpa Niinimäki ${ }^{1}$, Nathaniel Narra ${ }^{2}$, Laura Härkönen ${ }^{3}$, Shinya Abe ${ }^{4}$, Riku Nikander ${ }^{5,6,7}$, Jari Hyttinen ${ }^{2}$, Christopher Knüsel $^{8}$, Harri Sievänen ${ }^{9}$

\footnotetext{
${ }^{1}$ Archaeology, P.O.Box 1000, 90014 University of Oulu, Oulu, Finland;

${ }^{2}$ Department of Electronics and Communications Engineering, BioMediTech, Tampere University of Technology, Tampere, Finland;

${ }^{3}$ Department of Ecology and genetics, P.O.Box 3000, 90014 University of Oulu, Oulu, Finland;

${ }^{4}$ Laboratory of Civil Engineering, P.O. Box 600, Tampere University of Technology, 33101 Tampere, Finland;

${ }^{5}$ Department of Health Sciences, P.O BOX 35, 40014 University of Jyväskylä, Jyväskylä, Finland;

${ }^{6}$ GeroCenter Foundation for Aging Research and Development, Rautpohjankatu 8, 40700 Jyväskylä, Finland;

${ }^{7}$ Jyväskylä Central Hospital, Keskussairaalantie 19, 40620 Jyväskylä, Finland;

${ }^{8}$ De la Préhistoire à l'Actuel: Culture, Environnement, et Anthropologie (PACEA), UMR5199 PACEA, Bâtiment B8, Allée Géoffroy Saint Hilaire, CS 50023, Pessac Cedex, France 33615;

${ }^{9}$ The UKK Institute for Health Promotion Research, Kaupinpuistonkatu 1, P.O. Box 30, 33501 Tampere, Finland.
}

Corresponding author: Dr. Sirpa Niinimäki

Email: sirpa.niinimaki@oulu.fi

Archaeology, P.O.Box 1000, 90014 University of Oulu, Oulu, Finland;

Tel. +358442895120; Fax +358 8 344790; Email sirpa.niinimaki@oulu.fi

Grant sponsorship: Alfred Kordelin Foundation 


\begin{abstract}
Objectives: To investigate activity-induced effects in bone geometrical properties of the proximal femur in athletic versus non-athletic healthy females by statistically controlling for variation in body size, lower extremity isometric and dynamic muscle strength, and cross-sectional area of M. gluteus maximus.
\end{abstract}

Methods: The material consists of hip and proximal thigh magnetic resonance images of Finnish female athletes $(\mathrm{N}=91)$ engaged in either high-jump, triple-jump, soccer, squash, power-lifting, endurance running or swimming, and a group of active non-athletic women $(\mathrm{N}=20)$. Bone geometric properties were observed at the cross-sectional levels of lesser trochanter, sub-trochanter, and mid-shaft femur. Multiple regression analyses using the general linear model were performed for each bone property per cross-sectional level with body size, muscle size and muscle strength as covariates.

Results: Body size and isometric muscle strength were positively associated with bone properties at all cross-sectional levels, while muscle size was positively associated with bone properties only at femur mid-shaft. Triple-jump, soccer and squash resulted in greater values compared to non-athletes in all studied cross-sectional levels. At femur mid-shaft also high-jump and endurance running resulted in greater values compared to non-athletes. Swimmers had lower values in most bone properties compared to non-athletes at sub-trochanter and femur mid-shaft levels.

Conclusions: Activity effects via ground impact loading were associated with greater bone properties especially at femur mid-shaft, but also at lesser and sub-trochanter levels. Bone geometrical properties along the femur can be used to assess the mechanical stimuli experienced, where ground impact loading seems to be more important than muscle loading for osteogenic response.

Keywords: Physical activity, activity reconstruction, gravitational loading, muscle loading 


\section{INTRODUCTION}

Bone geometrical properties calculated from bone cross-sections - such as cortical area (CA), bending and torsional rigidity $(\mathrm{J})$, and ratio of second moment of inertia planes (shape) - are used to reconstruct physical activity in past populations (Ruff and Hayes, 1983; Stock and Pfeiffer, 2001; Holt, 2003; Weiss, 2003; Rhodes and Knüsel, 2005; Wescott and Cunningham, 2006; Ruff, 2008; Shaw and Stock, 2009). Variation in geometrical properties of bone are comprised indirectly of activity-induced changes in muscle size and strength, and directly of loading directions and rates, ground impacts, and intrinsically weight-bearing loads. In addition, biological factors such as body size/dimension, as well as hormonal and health factors, contribute to the observed variation. Understanding direct and indirect effects of activity coupled with the effects other factors have in bone geometrical properties will provide important insight on which aspects of activity can be reconstructed from the skeleton.

The underlying assumption for activity inferences from bone geometrical properties is that functional loading affects bone mass maintenance and distribution (Frost, 1987; Lanyon, 1989; Forwood and Burr, 1993; Lanyon, 1996; Martin, 2007). Increased loading can strengthen bones through increasing bone mass and cross-sectional area (Haapasalo et al., 2000; Kontulainen et al., 2002; Daly et al., 2004), while loading direction seems to associate more with cortical bone distribution (Niinimäki et al., 2013; Niinimäki et al., 2017) and bone cross-sectional shape (Ruff et al., 1994; Ruff, 2000a, 2003; Lieberman et al., 2004; Nikander et al., 2005; Ruff et al., 2006; Nikander et al., 2009; Rantalainen et al., 2010, Rantalainen et al., 2011; Narra et al., 2013). Mechanically strong and appropriate bone structures are achieved by exercise-induced skeletal adaptation at the loaded regions (Nikander et al., 2006).

Cross-sectional geometrical properties of bones scale also with body mass (Seeman et al., 1996; Schiess1 et al., 1998 et al., 2000; Schoenau and Frost, 2002; Parfitt, 2004; Petit et al., 2004): bone tissue is distributed proportionally further from the cross-sectional centroid with increased mass (Brianza et al., 2007). Weight-bearing can be considered intrinsic loading for the lower limb, as body weight determines the baseline for all gravitationally-induced mechanical stimuli from ground impacts. Bone cross-

sectional shape and strength adaptations are also influenced by body proportions, especially muscle moment arms (Ruff et al., 1994; Ruff, 2000a, 2000b, 2003; Weaver, 2003; Davies and Stock, 2014).

Muscle and bone properties maintain a similar relationship during growth (Daly et al., 2004). Although increase in muscle strength is not always caused by increase in the mass depending on the training scheme 
(Wilmore, 1974; Brown and Wilmore, 1974; Young et al., 1983, 1984, 1985; Hughes et al., 2001; Kongsgaard et al., 2004), the increase in strength is usually accompanied by the increase in mass (Young et al., 1983, 1984, 1985; Hughes et al., 2001; Kongsgaard et al., 2004; Kirk et al., 2007). Regarding activity, loading type can affect muscle mass and strength gain (Brown and Wilmore, 1974; Wilmore, 1974; Young et al., 1983; Chilibeck et al., 1998; Kongsgaard et al., 2004; Buford et al., 2007; Rønnestad et al., 2007; Van Roie et al., 2013; Niinimäki et al., 2016). Regarding activity reconstructions from bone geometrical properties, the relationship between muscle size and bone geometry has received some attention. As bone properties correlate with muscle mass (Shaw, 2010; Slizewski et al., 2013, 2014), Slizewski et al. $(2013,2014)$ suggested that CA could be used as a proxy for physical activity reconstructions. However, the large prediction errors with CA values have raised concern (Shaw, 2010). Furthermore, the process determining the association of the muscle size with the specific activity is not straightforward.

There are considerable mechanical stimuli to bone resulting from weight-bearing load, ground impacts and muscle activity (Kohrt et al., 2009; Niinimäki et al., 2017). High impact sports increase bone mass as well as muscle mass (Niinimäki et al., 2016; Niinimäki et al., 2017). Results from a recent study by Niinimäki et al. (2017) indicate that activities involving extreme ground impacts are associated with greater values in bone geometrical properties of the proximal femoral shaft. Beneficial results in terms of femoral neck strength were also found from extreme impact loading, and endurance runners, considered as a repetitive impact loading group in Abe et al. (2016). Loading comprises of magnitude and rate, where high strain rate is considered more important than strain magnitude (Lanyon \& Rubin 1984), as number and frequency of repetitions influence skeletal response (Lanyon, 1987, 1996; Umemura et al., 2002). Furthermore, strain distribution is important, where unusual loading directions are more osteogenic (Lanyon, 1987).

While it is appreciated that both gravitational and muscle loading results in bone responses, the debate is open over which of these loadings provides principally bone's response to mechanical stimuli due to lack of empirical studies on causality (Judex and Carlson, 2009; Robling, 2009). Therefore, regarding activity reconstructions, it is crucial to understand the aspects of activity that contribute to observable changes in bone geometrical properties.

The aim of this study is to observe the direct and indirect activity-induced variation in bone geometrical properties while statistically controlling for variation in body size and dimensions. Our sample consists 
of modern elite female athletes and non-athletic active females coupled with information on lower extremity muscle strength, $M$. gluteus maximus muscle size, and body size to examine how these considerations vary with biomechanically relevant morphological features of bone. Our material permits a targeted study on the proximal femur in its functional environment. This allows understanding on which aspects of activity can feasibly be reconstructed from the human skeleton. We utilize bone cross-sectional properties at lesser trochanter, sub-trochanter and femoral mid-shaft levels from magnetic resonance imaging (MRI) of the hip and proximal thigh.

\section{MATERIALS AND METHODS}

\section{Material}

The present study material comprised MR images (1.5T Avanto Syngo MR B15, Siemens, Erlangen, Germany) of previous hip (slice thickness $1.0 \mathrm{~mm}$, pixel size $0.9 * 0.9 \mathrm{~mm}$; Nikander et al., 2009) and thigh (slice thickness 3.0mm, pixel size $0.81 * 0.84 \mathrm{~mm}$; Sikiö et al., 2013) scans of 91 female athletes and 20 non-athletes. The athletes were recruited through their respective associations and clubs. The athletes' sports specific training history is described in Table 1. The age-matched controls were students recruited from local medical and nursing schools. The non-athlete females did not practice any sport at a competitive level and were involved in recreational physical activity two to three times a week (Table 1). The study protocol was approved by the Ethics Committee of Pirkanmaa Hospital District, and each participant gave written informed consent prior to the measurements.

Several sports representing different loading regimens were represented: 10 high-jumpers, 9 triplejumpers, 9 soccer players, 10 squash players, 17 power-lifters, 18 endurance runners, and 18 swimmers. Loading history was established by considering both typical sport performance and typical training. High-jump includes high ground impacts during typical sport performance and training (Nikander et al., 2009), where estimated vertical ground reaction force is 4 to 10 times BW (Martins et al., 2010). Triplejump involves extreme axial impacts to the ground (Nikander et al., 2009), and the peak vertical ground reaction force and its estimated loading rate involved in triple-jump is 12-20 times BW and 400-480 BW s$^{-1}$ (Heinonen et al., 2001; Ramey and Williams, 1985). Playing soccer and squash involves rapidly accelerating/decelerating movements and quick turns of the body that translate into more variable loading of the hip region, coupled with impacts with the ground (Nikander et al. 2005; Nikander et al., 2009). 
Their peak vertical ground reaction forces and its estimated loading rates are 2.5-3.5 times BW and 20$180 \mathrm{BW} \mathrm{s}^{-1}$ (Ball, 2013; Dayakidis and Boudolos, 2006; Smith et al., 2004). Long-distance running is an endurance sport that includes a great number of repetitive weight-bearing impacts to the ground with its peak ground reaction force 2-2.5 times BW and 60-150 $\mathrm{BW} \mathrm{s}^{-1}$ estimated loading rate (Kluitenberg et al., 2012; Logan et al., 2010; Munro et al., 1987), resulting in directionally consistent loading (Nikander et al., 2009). Power-lifting involves precisely coordinated movements coupled with maximal muscle force production (Nikander et al., 2009). In contrast with aforementioned exercise types, while powerlifting includes similar peak vertical ground reaction forces at 2-3 times BW, the estimated loading rate at 5-6 $\mathrm{BW} \mathrm{s}^{-1}$ in power-lifting are considerably lower (Swinton et al., 2012). In addition to the high static and transient low-rate loading of the bones, intense muscle forces also act to affect the loading within the proximal femur. Muscle activity during power-lifting likely also results in high compressive forces along the bone. Swimming is a non-impact sport, where the main loading arises from muscle contractions only, rather than the combined effects of muscle contraction and ground reaction forces (Nikander et al., 2009). Its peak reaction force and estimated loading rate at push-off phase of turning are estimated to be 1.5 times BW and < $10 \mathrm{BW} \mathrm{s}^{-1}$ (Blanksby et al., 1996; Lyttle et al., 1999). Competition and training in swimming consists of repetitive loading coming from muscle contraction only, i.e. without ground impacts.

\section{Bone geometrical properties}

The dominant take-off limb or the kicking limb of each participant was scanned. The cross-sectional contours of the cortical bone at these sites were extracted from the MR image data. Detailed information regarding the image data, image processing and feature extraction procedures are presented in Niinimäki et al. (2017).

Cortical area $\left(\mathrm{CA}\right.$, in $\mathrm{mm}^{2}$ ) associates to tensile and compressive loads. Second moment of area (I, in $\mathrm{mm}^{4}$ ), also called moment of inertia, represents bending rigidity at a given plane. Total area (TA, in $\mathrm{mm}^{2}$ ) was included to observe the potential of this measure for activity reconstructions, and to observe cortical versus total area differences. For this study, two moments of inertia planes were determined: $I_{\max }$ in the (approximate) direction of maximum shaft diameter and $I_{\min }$ in the (approximate) direction of minimum 
shaft diameter for lesser trochanter, sub-trochanter and femur mid-shaft. Torsional rigidity $\left(\mathrm{J}\right.$, in $\left.\mathrm{mm}^{4}\right)$ is derived from summing two perpendicular I's: i.e., $J=I_{\max }+I_{\min }$ (Ruff, 2003; O’Neill and Ruff, 2004).

The described bone properties were calculated for three cross-sections of the femur: lesser trochanter, sub-trochanter and femur mid-shaft (Fig. 1). Femur mid-shaft has been commonly used in evaluation of bone strength (e.g., Ruff et al., 1994; Ruff, 2000a, 2003). Femur mid-shaft was defined by predicting femoral length from its regression on stature (Niinimäki et al., 2017). Lesser trochanter and subtrochanter cross-sections were included as they serve as the attachments of several muscles resulting in movement of the femur in the hip joint, and thus, could be affected by muscle activity. Sub-trochanter cross-section is also likely influenced by body shape (Ruff, 2000b; Davies and Stock, 2014).

\section{Muscle properties}

MR images permit reliable observation of muscle area (Paalanne et al., 2011). The cranial portion of the M. gluteus maximus in the transverse plane was measured to represent its cross-sectional area at the level of the hip joint. This plane was chosen as it could be determined with reasonable accuracy with the help of anatomic landmarks (detailed description with accompanying illustration in Niinimäki et al., 2016). Furthermore, enlargement of the cranial portion of the M. gluteus maximus is specific to humans (Stern, 1972), and thus would provide a measurement with evolutionary meaning (Bramble and Lieberman, 2004). M. gluteus maximus is muscle that originates from the iliac crest and sacrum and inserts on the postero-lateral femoral shaft below the greater trochanter. It acts to extend the hip-joint (Gosling et al., 2002).

Muscle strength can be described both in terms of dynamic and isometric strength (Duchateau and Hainaut, 1984), and both strengths were evaluated as performance of lower extremity muscle strength in this study. Dynamic maximum take-off force was measured with a counter movement jump test on a force-plate (Kistler Ergojump 1.04, Kistler Instrumente AG, Winterthur, Switzerland). Isometric maximal lower limb extension force was measured with a leg press dynamometer and the knees initially flexed at a $90^{\circ}$ angle (Tamtron, Tampere, Finland; Nikander et al., 2009). These tests evaluate the performance of the lower extremities (Nagano et al., 2005; Reiman et al., 2012; Martelli et al., 2015). 


\section{Body dimensions}

Geometrical bone properties scale to body size, and thus are often adjusted (linearly) against weight (Ruff et al., 1994; Seeman et al., 1996; Schiessl et al., 1998; Schoenau et al., 2000; Shoenau and Frost, 2002; Parfitt, 2004; Petit et al., 2004), sometimes height (Feik et al., 1996), or a product of (reconstructed) body weight and muscle moment arm length (Ruff, 2000a, 2003). However, using only one body size variable provides a one-dimensional approach to scaling for body size, and the effects of other size components may remain biasing the variation remaining in bone geometrical properties (see Niinimäki et al. 2017). Thus, in this study, several measurements describing human body size were taken, and their variation was statistically combined using principal component analysis (PCA). Body height was measured against the wall with a tape measure and body mass (as weight) with scales at the same time as MR imaging was done (Nikander, 2006; Nikander et al., 2009). Skeletal measurements were obtained using the Osirix $32-$ bit program (http://www.osirix-viewer.com/Downloads.html). Axial, coronal and transverse planes could be re-oriented using the program to obtain bone measurements comparable to those taken from skeletal specimens. Bi-iliac breadth was measured as hemi breadth from the outer edge of the iliac blade to a line drawn at the middle of the sacrum (Niinimäki et al., 2017). This measurement multiplied by two yields a bi-iliac breadth (BIB) taken digitally (Martin and Saller 1957), and which is commonly used in body weight reconstructions (Ruff, 2000b; Ruff et al., 2005). Furthermore, BIB is known to affect proximal femur shaft shape (Weaver, 2003; Ruff, 200b; Shaw and Stock, 2011; Davies and Stock, 2014). Femoral head supero-inferior height (FHSI) was measured at the middle of the femoral caput for maximum diameter parallel to the angulation of the head (Martin and Saller, 1957). This measurement is considered to represent body weight and indicates skeletal robustness at the end of the longitudinal growth period (Ruff, 2003). Femoral head-neck length (FHNL) was measured from the most lateral point of the greater trochanter to the superior surface of the femoral caput (Martin and Saller, 1957; Lovejoy, 1975). This measurement contributes to body breadth and thus influences the moment arms of the muscles crossing the hip-joint (Ruff, 2005).

\section{Statistical analysis}

Prior to activity-induced analyses, we created a size variable that would capture the multidimensional nature of human body size (according to Niinimäki et al. 2017). Shortly, we performed PCA for the following measurements: body height, body weight, bi-iliac breadth (BIB), femoral head height (FHSI) and femoral head-neck length (FHNL). The only principal component (PC1) given by the procedure 
explained relatively well $(58.8 \%)$ the total variation in the body size. The obtained PC scores (i.e. extracted regression values) describe the correlational relationship between the included variables (Liu et al., 2003). Here, all size variables - body height in particular - loaded highly on the only principal component given by the procedure, thus providing a comprehensive summary of dimensional body size variation among the study subjects (Niinimäki et al., 2017).

To analyze activity-induced variation in the bone geometrical properties, we performed multiple regression analyses using the general linear model (GLM) procedure. The GLM fitted to the data for each bone property included lower extremity muscle strength (dynamic and isometric), body size (as PC1), and the gluteus area (cross-section of cranial portion of M. gluteus maximus) as covariates. Prior to analyses, all covariates were standardized to allow meaningful interpretation of models including multiple linear effects. Activity was used as a fixed factor, and the non-athletes were used as the reference category to estimate the activity-induced effects on the bone properties. The full models included all covariates, but all non-significant covariates were removed from the model according to the principle of parsimony (by always removing the least non-significant term from the model; $p<0.05$ ). The fit of the final models to the data was confirmed by inspecting the normality of model residuals. Logtransformation was required to obtain normality of residuals for $\mathrm{I}_{\max }$ at lesser trochanter; J, TA, $\mathrm{I}_{\min }$, and $I_{\max }$ at sub-trochanter; and $I_{\min }$, and $I_{\max }$ at femur mid-shaft. For between-group comparisons, estimated marginal means for each activity group, i.e. the remaining variation explained by between-group differences after variation due to all significant covariates is removed, were obtained from the final models. All the statistical analyses were performed in SPSS 25.0 for Windows (IBM SPSS Statistics for Windows, Version 25.0. Armonk, NY: IBM Corp. released 2017).

\section{RESULTS}

Descriptive data for each activity category is presented in Table 1. The strength and direction of each linear effect on each bone property are given in terms of regression coefficients in Table 2. Larger body

size (PC1) contributed to greater values in bone geometrical properties in all studied cross-sectional levels. While greater isometric strength had a significant positive effect on the observed bone properties, dynamic strength did not. Finally, larger muscle size predicted higher values in bone geometrical 
properties at the mid-shaft femur, except $\mathrm{I}_{\max }$ where muscle size did not affect observed variation (Table 2). All significant covariates had positive effects on the response variables (Table 2).

The effect of activity type (in comparison to non-athletes) on bone properties are presented in Figures 2a-2b. Differences were not observed in TA or $I_{\min }$ at lesser trochanter between athlete groups compared to non-athlete women (Figs. 2a-2b). All other bone geometrical properties in all other cross-sectional locations differed significantly according to activity (Table 2), when contrasted to non-athletes (Table 2, Figs. 2a-2b). To be more specific, the triple-jumpers had significantly greater values compared to the non-athletes in all bone properties and at cross-sectional levels, except TA at lesser trochanter and subtrochanter, and $I_{\min }$ at lesser trochanter (Figs. 2a-2b). The high-jumpers had greater values compared to the non-athletes in bone all properties but only at femur mid-shaft (Figs. 2a-2b). The soccer players had significantly greater values compared to the non-athletes in most bone properties at most cross-sectional levels, except in TA and $I_{\min }$ at lesser trochanter (Figs. 2a-2b). The squash players had significantly greater values compared to the non-athletes in most bone properties at most cross-sectional levels, except in TA, $I_{\min }$ and $I_{\max }$ at lesser trochanter (Figs. 2a-2b). The power-lifters did not differ significantly from the non-athletes (Figs. 2a-2b). The endurance runners had significantly greater bone properties at femur mid-shaft compared to the non-athletes (Figs. 2a-2b). Finally, the swimmers had significantly smaller values in $\mathrm{CA}$ and $\mathrm{J}$ at sub-trochanter and mid-shaft femur compared to the non-athletes, and significantly smaller $I_{\min }$ and $I_{\max }$ values at sub-trochanter cross-section (Figs. 2a-2b). When statistically significant difference between activity group and non-athletes were found, the athletes had greater values compared to non-athletes, except swimmers, which had smaller values compared to non-athletes, when significant (Figs. 2a-2b).

\section{DISCUSSION}

We were interested in the amount of variation remaining, and what might be attributable to different physical activities, after statistically controlling for variation due to body size, lower extremity muscle strength, and muscle size. Body size and lower extremity (isometric) strength had independent positive effects on bone geometrical properties of interest at all cross-sectional levels, while muscle size had a positive effect on all bone geometrical properties of interest only at femur mid-shaft (not for $I_{\max }$; Table 2). When variation due to body size and isometric muscle strength (and M. gluteus maximus muscle size, 
when relevant) was statistically controlled, the remaining variation was considered attributable to differences in other activity-induced effects. The influence of activity-induced effect, assumedly due to mechanical stimuli likely coming from ground impact, was especially evident at the femur mid-shaft (Table 2). This study provides relevant new information that the effects of activity on bone geometrical properties are not only due to indirect mechanisms via activity-induced increase in muscle size and strength, but that activity may also have a more direct effect on bone geometrical properties, which is likely attributable to ground impact loading, and the magnitude and frequency at which this takes place.

Triple-jump, soccer and squash were associated with greater CA and $\mathrm{J}$ values at all cross-sectional levels (also $I_{\min }$ and $I_{\max }$ at subtrochanter and TA, $I_{\min }$ and $I_{\max }$ at femur mid-shaft), regardless of the clear association of these values with lower extremity isometric muscle strength (and muscle size, when relevant), compared to non-athletes (Table 2; Figs. 2a-2b). At femur mid-shaft level, also high-jumpers and endurance runners had greater values in bone geometrical properties compared to non-athletes (Table 2a). This supports the assumption that greater bone geometrical property values observed among the participants of these sports result from ground impact loading encountered in their activity. Power-lifting was not associated with greater values in bone properties compared to non-athletes at any observed crosssectional locations. As referred from previous literature, while peak vertical ground reaction forces were similar in power-lifters compared to high-jumpers, soccer and squash players and endurance runners, the estimated loading rates were lower (Ball, 2013; Dayakidis and Boudolos, 2006; Kluitenberg et al., 2012; Logan et al., 2010; Munro et al., 1987; Smith et al., 2004; Swinton et al., 2012). Thus, bone osteogenic response likely arises from combined effects of ground reaction forces and loading rates, where both loading magnitude and frequency are important. Swimmers had significantly lower values in CA and J values at sub-trochanter and femur mid-shaft levels, and in $I_{\min }$ and $I_{\max }$ at sub-trochanter level) compared to non-athletes than would be linearly expected from their body size and lower extremity isometric muscle strength (and muscle size, when relevant; Table 2, Figs. 2a-2b). As swimming lacks all ground impacts, i.e. gravitational loading, it is apparent that muscle performance alone does not provide enough stimuli to increase bone geometric properties at the proximal half of the femur. Thus, these results offer firm support for impact loading resulting from ground reaction forces as relevant factors generating major osteogenic stimuli for the lower extremities (Lanyon, 1987; Nikander et al., 2005, 2006, 2009; Shaw and Stock, 2009; Niinimäki et al., 2017). 
Greater lower extremity isometric muscle strength was associated with greater values of bone geometrical properties (Table 2). There is a close relationship between muscle size and muscle strength indicated in previous research, where an increase in strength is accompanied with an increase in size (Wilmore, 1974; Brown and Wilmore, 1974; Young et al., 1983, 1984, 1985; Frontera et al., 1991; Burr 1997; Chilibeck et al., 1998; Hughes et al., 2001; Kongsgaard et al., 2004; Kirk et al., 2007). In our previous study (Niinimäki et al., 2016), we found a positive correlation between muscle isometric strength and M. gluteus maximus cross-sectional area, but the effect of dynamic strength on M. gluteus maximus cross-sectional area was dependent on body weight: the slope of the regression of muscle size to dynamic force was steepest amongst heaviest tertile of individuals (Niinimäki et al., 2016). Dynamic and isometric strength are muscle strength indicators, but dynamic strength effects are dependent on size. Thus, only isometric strength remained a significant muscle covariate in the final models.

We found that muscle size as M. gluteus maximus cross-sectional area contributed to variation in bone properties only in femur mid-shaft (Table 2). Thus, our study provides new insights to the debate over whether muscle loading or gravitational loading is the main source of mechanical stimuli on bone's response (Judex and Carlson, 2009; Robling, 2009). When these current results are interpreted in conjunction with the results of our previous works (Niinimäki et al., 2016, 2017), it seems that while muscle loading provides enough stimuli to result in greater bone property values among power-lifters compared to non-athletes (Niinimäki et al. 2017), the lower estimated loading rates in power-lifting results in statistically similar values in bone properties compared to non-athletes, when variation due to their greater muscle strength (and size) was accounted for. On the contrary, among triple-jumpers, and soccer and squash players there is still a significant source of mechanical stimuli resulting in differences in bone properties compared to non-athletes when muscle loading is accounted for (Table 2, Figs. 2a2b). In addition, when statistically controlling for greater M. gluteus maximus cross-sectional areas among high-jumpers in evaluations of femoral mid-shaft, high-jumpers still had significantly greater bone properties compared to non-athletes (Figs. 2a-2b). In addition, endurance runners had greater values compared to non-athletes in the femur mid-shaft (Figs. 2a-2b). However, it should be noted that the number of individuals in high-jump, triple-jump, soccer and squash was less than ten (Table 1). While swimming is known to result in marked changes in non-weight bearing humeral shaft shape and therefore strength (Nikander, 2006; Shaw and Stock, 2009), this is not the case for the weight-bearing proximal femur (Niinimäki et al., 2017). Greater muscle size among swimmers (Niinimäki et al., 2016) did not result in greater bone properties compared to non-athletes even when not controlling for the effects of 
muscle size (Nikander et al., 2006; Nikander et al., 2009; Niinimäki et al., 2016). Thus, these results support the importance of gravitational loading over muscle loading as the main source of mechanical stimuli. Furthermore, when effects of gravitational loading are considered in terms of loading magnitude (as peak vertical ground reaction forces) and frequency (repetitiveness), both components are important for osteogenic response especially at femur mid-shaft.

Variation in bone geometrical properties due to activity was most evident in the femoral mid-shaft (Figs. $2 \mathrm{a}-2 \mathrm{~b}$ ). Also, the effects of muscle size were evident in the femoral mid-shaft (Table 2). At the lesser trochanter, bone properties of swimmers were not significantly lower compared to non-athletes (Figs. $2 \mathrm{a}-2 \mathrm{~b})$. This was evident also for the femoral neck region: femoral neck strength among swimmers is similar to non-athletes, while femoral neck strength among athletes engaged in any kind of impact loading is greater compared to non-athletes (Abe et al., 2016). Thus, selection of cross-sectional location also affects what is discernible (intensity of ground impact effects relative to muscle loading effects). Only the most vigorous ground impact loading with high loading rates results in differences in proximal femur bone properties when body size, lower extremity muscle strength and muscle size are accounted for (Table 2).

Our results indicate the importance of ground reaction forces for maintenance and accrual of bone mass, and thus concur with previous research (Andreoli et al., 2001; Duncan et al., 2002; Nikander et al., 2005; Nikander et al., 2006; Daly et al., 2007, Martin 2007, Nikander et al., 2009; Narra et al., 2013; Abe et al., 2016). Regarding activity reconstructions, this further underlines the importance of considering ground impact effects as a relevant source of osteogenic stimuli. Thus, suggestion of Slizewski et al. $(2013,2014)$ that CA could be used to reconstruct physical activity via reconstructing muscle size does not appreciate activity effects coming from sources other than muscle area (e.g. gravitational loading and indirect effects of muscle size and strength). Bone geometric properties may be more informative interpreted through their responsivity to impact loading and loading frequency - possibly also coupled with information in different regions - to gain more informative activity reconstructions.

\section{CONCLUSIONS}

The results of this study indicate that there is variation in bone geometric properties even after removing the variation due to individual differences in body size, lower extremity muscle strength, and muscle 
size. The residual variation can at least in part be attributable to differences between non-athletes and specific athletic activities. This variation likely arises from specific features of ground reaction forces, and the magnitude and frequency at which the loading occurs during these activities. Greater bone geometrical properties were found in high-jumpers, triple-jumpers, soccer and squash players, and endurance runners compared to non-athletes at femoral mid-shaft, thus likely associated with high ground impact loading and high loading rates. However, bone properties of high-jumpers and endurance runners were proportional to lower extremity isometric muscle strength and body size at lesser trochanter and sub-trochanter levels compared to non-athletes. Compared to aforementioned activities where bone properties were greater compared to non-athletes, training and competition in power-lifting includes little ground impact loading, while swimming lacks it completely. This likely explains why bone geometrical properties were similar (or, in case of swimmers, smaller) compared to non-athletic but active individuals. Thus, it seems that while an increase in lower extremity isometric muscle strength and muscle size is related to the general activity level of an individual, they do not solely explain greater bone geometrical properties compared to non-athletes. The differences are likely induced by high ground impact loading with high loading rates, and these loading effects are most evident in femur mid-shaft. Nonetheless, activities normally have components of loading from weight-bearing, ground impacts and muscle activity - but to varying degrees. While it may not be possible to distinguish the different sources of loading stimuli from archaeological skeletal remains, greater or lesser mechanical stimuli can be evaluated based on bone geometry of skeletal remains.

\section{ACKNOWLEDGEMENTS}

This research was funded by the Alfred Kordelin Foundation.

\section{Author contributions}

SN, HS and RN designed the study, and directed implementation and data collection. SN, NN, LH, and SA analysed the data. SN drafted the manuscript. NN, HS, CK, JH, RN, SA and LH edited the manuscript for intellectual content and provided critical comments on the manuscript. 


\section{REFERENCES}

Abe, S., Narra, N., Nikander, R., Hyttinen, J., Kouhia, R., Sievänen, H. (2016). Exercise loading history and femoral neck strength in a sideways fall: A three-dimensional finite element modeling study. Bone 92, 9-17.

Andreoli, A., Monteleone, M., Van Loan, M., Promenzio, L., Tarantino, U., de Lorenzo, A. (2000). Effects of different sports on bone density and muscle mass in highly trained athletes. Medicine \& Science in Sports \& Exercise, 33, 507-511.

Ball, K. (2013). Loading and performance of the support leg in kicking. Journal of Science and Medicine in Sport, 16, 455-459.

Blanksby, B.A., Gathercole, D.G., Marshall, R.N. (1996). Force plate and video analysis of the tumble turn by age-group swimmers. Journal of Swimming Research, 11, 40-45.

Bramble, D.M., Lieberman, D.E. (2004). Endurance running and the evolution of Homo. Nature, 18, 345-52.

Brianza, S.Z.M., D’Amelio P, Pugno N, Delise M, Bignardi C, Isaia G. (2007). Allometric scaling and biomechanical behaviour of the bone tissue: an experimental intraspecific investigation. Bone, 40, 16351642.

Brown, C., Wilmore, J.H. (1974). The effects of maximal resistance training on the strength and body composition of women athletes. Medicine \& Science in Sports \& Exercise, 6, 174-177.

Buford, T.W., Rossi, S.J., Smith, D.B., Warren, A.J. (2007). A comparison of periodization models during nine weeks with equated volume and intensity for strength. Journal of Strength and Conditioning Reseach, 21, 1245-1250.

Burr, D.B. (1997). Muscle strength, bone mass, and age-related bone loss. Journal of Bone and Mineral al Research, 12, 1547-1551.

Chilibeck, P.D., Calder, A.W., Sale, D.G., Webber, C.E. (1998). A comparison of strength and muscle mass increases during resistance training in young women. European Journal of Applied Physiology, 77, 170-175.

Daly, R.M., Saxon, L., Turner, C.H., Robling, A.G. Bass, S.L. (2004). The relationship between muscle size and bone geometry during growth and in response to exercise. Bone, 34, 281-287.

Daly, R. (2007). The Effect of Exercise on Bone Mass and Structural Geometry during Growth. In Daly, R. \& Petit, M. (eds.) Optimizing Bone Mass and Strength. The Role of Physical Activity and Nutrition during Growth. Medicine and Sport Science, 51, 33-49. 
Davies, T.G., Stock, J.T. (2014). The influence of relative body breadth on the diaphyseal morphology of the human lower limb. American Journal of Human Biology, 26, 822-35.

Dayakidis, M.K., Boudolos, K. (2006). Ground reaction force data in functional ankle instability during two cutting movements. Clinical Biomechanics, 21, 405-411. doi:10.1016/j.clinbiomech.2005.11.010

Duchateau, J., Hainaut, K. (1984). Isometric or dynamic training: differential effects on mechanical properties of a human muscle. Journal of Applied Physiology: Respiratory, Environmental and Exercise Physiology, 56(2), 296-301.

Duncan, G.S., Blimke, C.R.J., Cowell, C.T., Burke, S.T., Briody, J.N., Howman-Giles, R. (2002). Bone and Mineral al density in adolescent female athletes: relationship to exercise type and muscle strength. Medicine \& Science in Sports Exercise, 34(2), 286-294.

Feik, S.A., Thomas, C.D.L., Clement, J.G. (1996). Age trends in remodeling of the femoral midshaft differ between the sexes. Journal of Orthopaedic Research, 14, 590-597.

Forwood, MR, Burr DB. (1993). Physical activity and bone mass: exercises in futility? Bone and Mineral 21, 89-112.

Frontera, W.R., Hughes, V.A., Lutz, K.J., Evans, W.J., (1991). A cross-sectional study of muscle strength and muscle mass in 45- to 78-yr-old men and women. Journal of Applied Physiology, 71, 644-650.

Frost, H.M. (1987). Bone "mass" and the "mechanostat". A proposal. The Anatomical Record, 219, 1-9.

Gosling, J.A., Harris, P.F., Whitmore, I., Willan, P.L.T. (2002). Human anatomy color atlas and text. (4th ed.). Mosby. Elsevier Science Limited.

Haapasalo H, Kontulainen S, Sievänen H, Kannus P, Järvinen JA, Vuori I. (2000). Exercise-induced bone gain is due to enlargement in bone size without a change in volumetric bone density: a peripheral quantitative computed tomography study of the upper arms of male tennis players. Bone, 27(3), 351357.

Heinonen A, Sievänen H, Kyröläinen H, Perttunen J, Kannus P. (2001). Mineral mass, size, and estimated mechanical strength of triple-jumpers' lower limb. Bone, 29, 279-285.

Holt, B.M. (2003). Mobility in Upper Paleolithic and Mesolithic Europe: evidence from the lower limb. American Journal of Physical Anthropology, 122, 200-215.

Hughes, V.A., Frontera, W.R., Wood, M., Evans, W.J., Dallal, G.E., Roubenoff, R., Fiatarone Singh, M.A. (2001). Longitudinal muscle strength changes in older adults: influence of muscle mass, physical activity and health. J. Gerontol. Journals of Gerontology Series - A Biological Sciences and Medical Sciences, 56, B209-B217.

IBM SPSS Statistics for Windows, Version 25.0. Armonk, NY: IBM Corp. released 2017. 
Judex, S., Carlson, K.J., (2009). Is bone's response to mechanical signals dominated by gravitational loading. Medicine \& Science in Sports \& Exercise 41, 2037-2043.

Kirk, E.P., Washburn, R.A., Bailey, B.W., LeCheminant, J.D., Donnelly, J.E., (2007). Six months of supervised high-intensity low-volume resistance training improves strength independent of changes in muscle mass in young overweight men. Journal of Strength and Conditioning Research, 21, 151-156.

Kluitenberg, B., Bredeweg, S.W., Zijlstra, S., Zijlstra, W., Buist, I., (2012). Comparison of vertical ground reaction forces during overground and treadmill running. A validation study. BMC Musculoskeletal Disorders, 13, 235. doi:10.1186/1471-2474-13-235

Kohrt, W., Barry, D.W., Schwartz, R.S. (2009). Muscle Forces or Gravity: What Predominates Mechanical Loading on Bone? Medicine \& Science in Sports \& Exercise, 41, 2050-2055.

Kongsgaard, M., Backer, V., Joergensen, K., Kjaer, M., Beyer, N., (2004). Heavy resistance training increases muscle size, strength and physical function in elderly male COPD-patients - a pilot study. Respiratory Medicine, 98, 1000-1007.

Kontulainen, S., Sievänen, H., Kannus, P., Pasanen, M., Vuori, I. (2002). Effect of long-term impactloading on mass, size, and estimated strength of humerus and radius of female racquet-sports players: a peripheral quantitative computed tomography study between young and old starters and controls. Journal of Bone and Mineral Research, 18, 352-359.

Lanyon, L.E. (1987). Functional strain in bone tissue as an objective and controlling stimuli for adaptive bone remodeling. Journal of Biomechanics, 20, 1083-1093.

Lanyon, L.E. (1996). Using functional loading to influence bone mass and architecture: objectives, mechanisms, and relationship with estrogen of the mechanically adaptive process in bone. Bone, 18 Supp 11, S37-S43.

Lanyon, L.E., Rubin, C.T., (1984). Static vs dynamic loads as an influence on bone remodeling. Journal of Biomechanics 17, 897-905.

Lieberman, D.E., Polk, J.D., Demes, B. (2004). Predicting long bone loading from cross-sectional geometry. American Journal of Physical Anthropology, 123, 156-171.

Liu, R.X., Kuang, J., Gong, Q., Hou, X.L. (2003). Principal component regression analysis with SPSS. Computer Methods and Programs in Biomedicine, 71, 141-7.

Logan, S., Hunter, I., Hopkins, J.T., Feland, J.B., Parcell, A.C., (2010). Ground reaction force differences between running shoes, racing flats, and distance spikes in runners. Journal of Sports Sciece and Medicine, 9, 147-153. doi:10.1055/s-0033-1338501

Lovejoy, C.O. (1975). Biomechanical perspective on the lower limb of early hominids. In: Primate functional morphology and evolution. Tuttle RH (ed.), pp. 291-326. The Hague: Mouton. 
Lyttle, A.D., Blanksby, B.A., Elliott, B.C., Lloyd, D.G., (1999). Investigating kinetics in the freestyle flip turn push-off. Journal of Applied Biomechanics, 15, 242-252.

Martelli, S., Calvetti, D., Somersalo, E., Viceconti, M. (2015). Stochastic modelling of muscle recruitment during activity. Interface Focus, 5(2), 20140094.

Martin, R.B. (2007). The importance of mechanical loading in bone biology and medicine. Journal of Musculoskeletal and Neuronal Interactions, 7(1), 48-53.

Martin, R., Saller, K. (1957). Lehrbuch der Anthropologie, Band I. Stuttgart: Fischer.

Martins, S., Carvalho, J., Conceicao, F. (2010). Insights of take-off of ground reaction force in high jump. XXVIII Internacional Symposium on Biomechanics in Sports. DOI: 10.13140/2.1.2401.7922.

Munro, C.F., Miller, D.I., Fuglevand, A.J., (1987). Ground reaction forces in running: A reexamination. Journal of Biomechanics, 20, 147-155. doi:10.1016/0021-9290(87)90306-X

Nagano, A., Komura, T., Fukashiro, S., Himeno, R., (2005). Force, work and power output of lower limb muscles during human maximal-effort countermovement jumping. Journal of Electromyography and Kinesiology, 15, 367-76.

Narra, N., Nikander, R., Viik, J., Hyttinen, J., Sievänen, H. (2013). Femoral neck cross-sectional geometry and exercise loading. Clinical Physiology and Functioning Imaging, 33, 258-266.

Nikander, N., Sievänen, H., Heinonen, A., Kannus, P. (2005). Femoral neck structure in adult female athletes subjected to different loading modalities. Journal of Bone and Mineral Research, 20, 520-528.

Nikander, N., Sievänen, H., Uusi-Rasi, K., Heinonen, A., Kannus, P. (2006). Loading modalities and bone structures at nonweight-bearing upper extremity and weight-bearing lower extremity: A pQCT study of adult female athletes. Bone, 39, 886-894.

Nikander, R., Kannus, P., Dastidar, P., Hannula, M., Harrison, L., Cervinka, T., Narra, N.G., Aktour, R., Arola, T., Eskola, H., Soimakallio, S., Heinonen, A., Hyttinen, J., Sievänen, H. (2009). Targeted exercises against hip fragility. Osteoporosis International, 20, 1321-1328.

Niinimäki, S., Narra, N., Härkönen, L., Nikander, R., Abe, S., Knüsel, C., Sievänen, H. (2017). The relationship between loading history and proximal femoral diaphysis cross-sectional geometry. American Journal of Human Biology, DOI: 10.1002/ajhb.22965.

Niinimäki, S., Härkönen, L., Nikander, R., Abe, S., Knüsel, C., Sievänen, H. (2016). The relationship between habitual exercise loading types and cross-sectional area of the Gluteus maximus muscle among adult female athletes. HOMO, 67(2), 125-3.

Niinimäki, S., Södering, S., Junno, J.-A., Finnilä, M., Niskanen, M. (2013). Cortical bone thickness can adapt locally to muscular loading while changing with age. HOMO, 64, 474-490. 
O’Neill, M.C., Ruff, C.B. (2004). Estimating human long bone cross-sectional geometric properties. A comparison of noninvasive methods. Journal of Human Evolution, 47, 221-233.

Paalanne, N., Niinimäki, J., Karppinen, J., Taimela, S., Mutanen, P., Takasalo, J., Korpelainen, R., Tervonen, O. (2011). Assessment of association between low back pain and paraspinal muscle atrophy using opposed-phase magnetic resonance imaging. Spine, 36, 1961-1968.

Parfitt, A.M. (2004). The attainment of peak bone mass: what is the relationship between muscle growth and bone growth? Bone, 34, 767-770.

Petit, M.A., Beck, T.J., Lin, H.-M., Bentley, C., Legro, R.S., Lloyd. T. (2004). Femoral bone structural geometry adapts to mechanical loading and is influenced by sex steroids: the Penn State young women's health study. Bone, 35, 750-759.

Ramey, M.R., Williams, K.R. (1985). Ground Reaction Forces in the Triple-jump. International Journal of Sport Biomechanics, 1, 233-239.

Rantalainen, T., Nikander, R., Heinonen, A., Suominen, H., Sievänen, H. (2010). Direction-specific diaphyseal geometry and mineral mass distribution of tibia and fibula: a pQCT study of female athletes representing different exercise loading types. Calcified Tissue International, 86, 447-454.

Rantalainen, T., Nikander, R., Daly, R.M., Heinonen, A., Sievänen, H. (2011). Exercise loading and cortical bone distribution at the tibial shaft. Bone, 48, 786-791.

Reiman, M.P., Bolgla, L.A., Loudon, J.K. (2012). A literature review of studies evaluating gluteus maximus and gluteus medius activation during rehabilitation exercises. Physiotherapy Theory and Practice, 28, 257-268.

Rhodes, J.A., Knüsel, C.J. (2005). Activity-related skeletal change in medieval humeri: cross-sectional and architectural alterations. American Journal of Physican Anthropology, 128, 536-546.

Robling, A., (2009). Is bone's response to mechanical signals dominated by muscle forces. Medicine \& Science in Sports \& Exercise 41, 2044-2049.

Ruff, C.B. (2000a). Body size, body shape, and long bone strength in modern humans. Journal of Human Evolution, 38, 269-290.

Ruff, C.B. (2000b). Body mass prediction from skeletal frame size in elite athletes. American Journal of Physical Anthropology, 113, 507-517.

Ruff, C.B. (2002): Variation in human body size and shape. Annual Review of Anthropology, 31, 211232.

Ruff, C.B. (2005). Mechanical determinants of bone form: insights from skeletal remains. Journal of Musculoskeletal and Neuronal Interactions, 5(3), 202-212. 
Ruff, C.B. (2008). Femoral/humeral strength in early African Homo erectus. Journal of Human Evolution, 54, 383-390.

Ruff, C.B., Hayes, W. (1983). Cross-sectional geometry of Pecos Pueblo femora and tibiae - a biomechanical investigation. I. Method and general patterns of variation. American Journal of Physical Anthropology, 60, 359-381.

Ruff, C.B., Walker, A., Trinkaus, E. (1994). Postcranial robusticity in Homo. III: Ontogeny. American Journal of Physical Anthropology, 93, 35-54.

Ruff, C., Niskanen, M., Junno, J.-A., Jamison, P. (2005). Body mass prediction from stature and bi-iliac breadth in two high latitude populations, with applications to earlier higher latitude humans. Journal of Human Evolution, 48, 381-392.

Ruff, C., Holt, B., Trinkaus, E. (2006). Who's afraid of the Big Bad Wolff? "Wolff's law" and bone functional adaptation. American Journal of Physical Anthropology, 129, 484-498.

Rønnestad, B.R., Eqeland, Q., Kvamme, N.H., Refsnes, P.E., Kadi, F., Raastad, T., (2007). Dissimilar effects of one and threeset strength training on strength and muscle mass gains in upper and lower body in untrained subjects. Journal of Strength and Conditioning Research, 21, 157-163.

Schiessl, H., Frost, H.M., Jee, W.S.S. (1998). Estrogen and bone-muscle strength and mass relationships. Bone, 22, 1-6.

Schoenau, E., Frost, H.M. (2002). The "muscle-bone unit" in children and adolescents. Calcified Tissue International, 70, 405-407.

Schoenau, E., Neu, C.M., Mokov, E., Wassmer, G., Manz, F. (2000). Influence of puberty on muscle area and cortical area of the forearm in boys and girls. Journal of Clinical Endocrinology \& Metabolism, 85, 1095-1098.

Seeman, E., Hopper, J.L., Young, N.R., Formica, C., Goss, P., Tsalamandris, C. (1996). Do genetic factors explain associations between muscle strength, lean mass, and bone density? A twin study. American Journal of Physiology-Endocrinology and Metabolism, 270, E320-E327.

Shaw, C.N. (2010). 'Putting flesh back onto the bones?' Can we predict soft tissue properties from skeletal and fossil remains? Journal of Human Evolution, 59, 484-492.

Shaw, C.N., Stock, J.T. (2009). Habitual throwing and swimming corresponds with upper limb diaphyseal strength and shape in modern human athletes. American Journal of Physical Anthropology, 140, 160-172.

Shaw, C.N., Stock, J.T. (2011). The influence of body proportions on femoral and tibial midshaft shape in hunter-gatherers. American Journal of Physical Anthropology, 144, 22-29. 
Slizewski, A., Schoenau, E., Shaw, C., Harvati, K. (2013). Muscle area estimation from cortical bone. The Anatomical Record, 296, 1695-1707.

Slizewski, A., Burger-Heinrich, E., Francken, M., Wahl, J., Harvati, K. (2014). Pilot study for reconstruction of soft tissues: muscle cross-sectional area of the forearm estimated from cortical bone for a Neolithic sample. The Anatomical Record, 297, 1103-1114.

Smith, N., Dyso, R., Janaway, L. (2004). Ground reaction force measures when running in soccer boots and soccer training shoes on a natural turf surface. Sports Engineering, 7, 159-167. doi:10.1007/BF02844054

Stern, J.T. (1972). Anatomical and functional specializations of the human gluteus maximus. American Journal of Physical Anthropology, 36, 315-340.

Stock JT, Pfeiffer S. (2001). Linking structural variability in long bone diaphyses to habitual behaviors: foragers from the Southern African Later Stone Age and the Andaman Islands. American Journal of Physical Anthropology, 115, 337-348.

Swinton, P.A., Lloyd, R., Keogh, J.W., Agouris, I., Stewart, A.D., (2012). A biomechanical comparison of the traditional squat, powerlifting squat, and box squat. Journal of Strength \& Conditioning Research, 26, 1805-1816.

Umemura, Y., Sogo, N., Honda, A., (2002). Effects of intervals between jumps or bouts on osteogenic response to loading. Journal of Applied Physiology 93, 1345- 1348.

Van Roie, E.V., Delecluse, C., Coudyzer, W., Boonen, S., Bautmans, I., (2013). Strength training at high versus low external resistance in older adults: effects on muscle volume, muscle strength, and forcevelocity characteristics. Experimental Gerontology, 48, 1351-1361.

Weaver, T.D. (2003). The shape of the Neandertal femur is primarily the consequence of a hyperpolar body form. Proceedings of National Academy of Sciences, 100(12), 6926-6929.

Weiss E. (2003). Effects of rowing on humeral strength. American Journal of Physical Anthropology, 121, 293-302.

Wescott, D.J., Cunningham, D.L. (2006). Temporal changes in Arikara humeral and femoral crosssectional geometry associated with horticultural intensification. Journal of Archaeolical Science, 33(7), 1022-1036.

Wilmore, J.H. (1974). Alterations in strength, body composition and anthropometric measurements consequent to a 10-week weight training program. Medicine \& Science in Sports \& Exercise, 6, 133-138.

Young, A., Stokes, M., Round, J.M., Edwards, R.H. (1983). The effects of high-resistance training on the strength and cross-sectional area of the human quadriceps. European Journal of Clinical Investigation, 13, 411-417. 
Young, A., Stokes, M., Crowe, M. (1984). Size and strength of the quadriceps muscles of old and young women. European Journal of Clinical Investigation, 14, 282-287.

Young, A., Stokes, M., Crowe, M. (1985). The size and strength of the quadriceps muscles of old and young men. Clinical Physiology, 5, 145-154. 


\section{Tables}

Table 1. Descriptive variables by groups with mean \pm SD indicated.

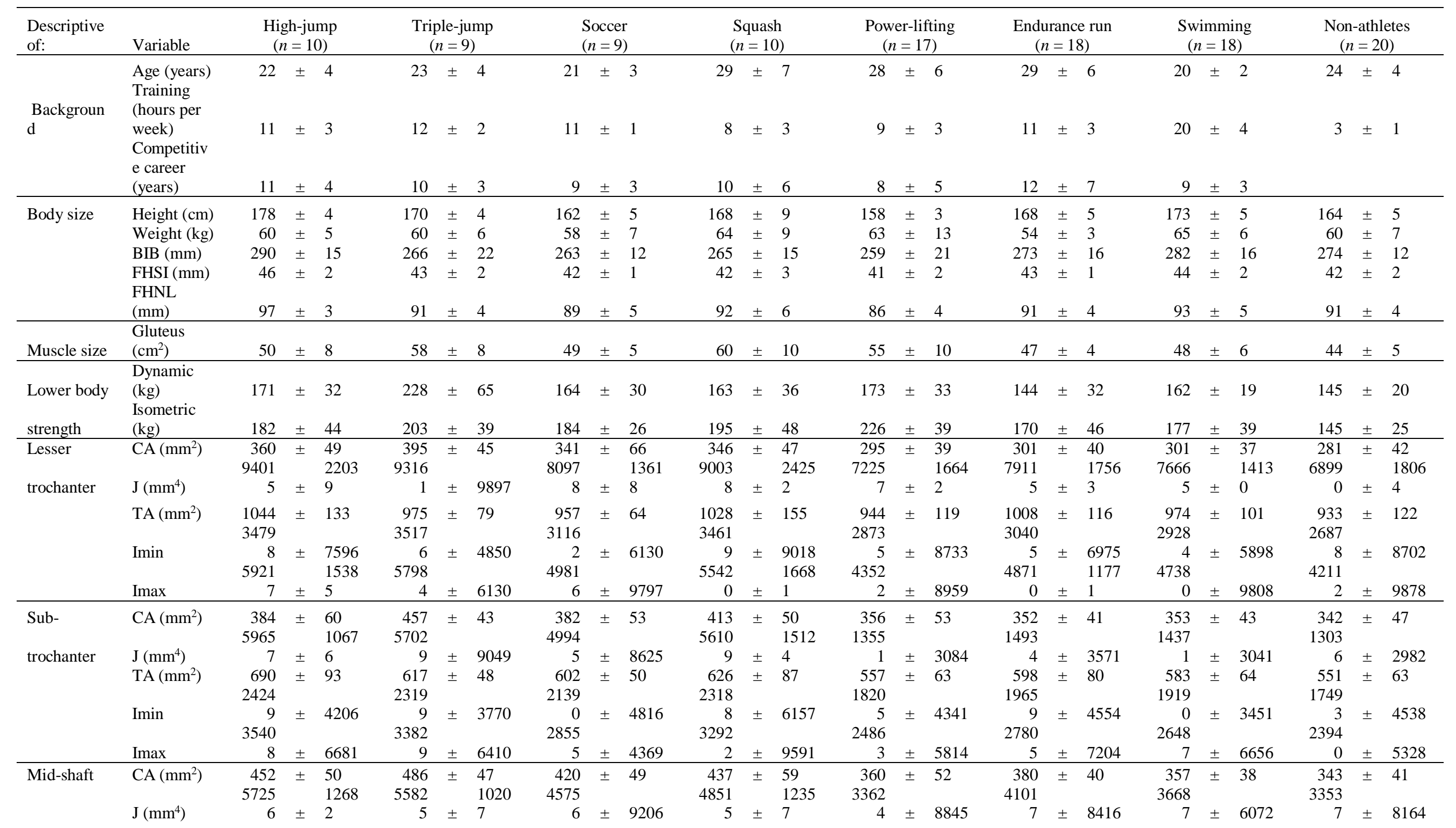




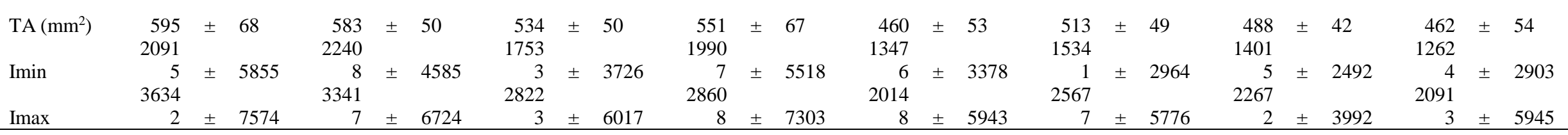


Table 2. Final general linear models explaining variation in bone properties.

\begin{tabular}{|c|c|c|c|c|c|c|c|c|c|c|c|c|c|c|c|}
\hline \multirow[b]{2}{*}{ Variable } & \multirow[b]{2}{*}{ Location } & \multicolumn{4}{|c|}{ Body size (PCA) } & \multicolumn{4}{|c|}{ Isometric strength } & \multicolumn{3}{|c|}{ Gluteus muscle size } & \multirow[b]{2}{*}{$\mathbf{P}$} & \multicolumn{2}{|c|}{ Activity } \\
\hline & & $b$ & & SE & $\mathbf{P}$ & $b$ & & SE & $\mathbf{P}$ & $b$ & & SE & & $\mathrm{EMM} \pm \mathrm{SE}$ & $\mathbf{P}$ \\
\hline \multirow[t]{3}{*}{$\mathrm{CA}$} & Lesser & 22.699 & \pm & 4.997 & $<0.001$ & 16.056 & \pm & 4.478 & 0.001 & & & & NS & Fig. $2 \mathrm{a}$ & $<0.001$ \\
\hline & Sub & 31.421 & \pm & 5.136 & $<0.001$ & 17.236 & \pm & 4.603 & $<0.001$ & & & & NS & Fig. 2a & $<0.001$ \\
\hline & Mid & 28.857 & \pm & 4.833 & $<0.001$ & 11.502 & \pm & 4.309 & 0.009 & 11.628 & \pm & 5.135 & 0.026 & Fig. $2 \mathrm{a}$ & $<0.001$ \\
\hline \multirow[t]{3}{*}{$\mathrm{J}$} & Lesser & 11812.042 & \pm & 1754.739 & $<0.001$ & 6012.865 & \pm & 1572.608 & $<0.001$ & & & & NS & Fig. 2a & 0.001 \\
\hline & Sub (log) & 0.080 & \pm & 0.009 & $<0.001$ & 0.034 & \pm & 0.008 & $<0.001$ & & & & NS & Fig. 2a & $<0.001$ \\
\hline & Mid & 6470.280 & \pm & 909.147 & $<0.001$ & 1836.565 & \pm & 810.573 & 0.026 & 2294.922 & \pm & 965.952 & 0.019 & Fig. 2a & $<0.001$ \\
\hline \multirow[t]{3}{*}{ TA } & Lesser & 75.389 & \pm & 12.392 & $<0.001$ & 36.105 & \pm & 11.106 & 0.002 & & & & NS & Fig. 2a & 0.050 \\
\hline & Sub (log) & 0.041 & \pm & 0.005 & $<0.001$ & 0.014 & \pm & 0.004 & 0.001 & & & & NS & Fig. 2a & $<0.001$ \\
\hline & Mid & 37.632 & \pm & 5.318 & $<0.001$ & 12.145 & \pm & 4.742 & 0.012 & 12.681 & \pm & 5.650 & 0.027 & Fig. 2a & $<0.001$ \\
\hline \multirow[t]{3}{*}{ Imin } & Lesser & 4111.310 & \pm & 792.174 & $<0.001$ & 2870.523 & \pm & 709.952 & $<0.001$ & & & & NS & Fig. 2b & 0.015 \\
\hline & Sub $(\log )$ & 0.084 & \pm & 0.009 & $<0.001$ & 0.032 & \pm & 0.009 & $<0.001$ & & & & NS & Fig. 2b & $<0.001$ \\
\hline & Mid (log) & 0.065 & \pm & 0.010 & $<0.001$ & 0.033 & \pm & 0.009 & $<0.001$ & 0.022 & \pm & 0.011 & 0.038 & Fig. 2b & $<0.001$ \\
\hline \multirow[t]{3}{*}{ Imax } & $\begin{array}{l}\text { Lesser } \\
(\log )\end{array}$ & 0.067 & \pm & 0.010 & $<0.001$ & 0.027 & \pm & 0.009 & 0.004 & & & & NS & Fig. 2b & 0.003 \\
\hline & Sub $(\log )$ & 0.076 & \pm & 0.009 & $<0.001$ & 0.035 & \pm & 0.008 & $<0.001$ & & & & NS & Fig. 2b & $<0.001$ \\
\hline & Mid (log) & 0.074 & \pm & 0.010 & $<0.001$ & 0.022 & \pm & 0.009 & 0.021 & & & & NS & Fig. 2b & $<0.001$ \\
\hline
\end{tabular}

* Full model included the body size variable (PC1), isometric strength, dynamic strength, $M$. gluteus maximus cross-sectional area as covariates, and activity as a categorical variable. 


\section{Figure legends}

Figure 1. The anatomical locations identified for performing cross-sectional analysis of the bone biomechanical properties at the level of lesser trochanter, at sub-trochanter level and mid-shaft femur.

Figure 2a. Estimated marginal means with $95 \%$ confidence intervals for cortical area (CA), bending and torsion rigidity $(\mathrm{J})$ and total area (TA) at lesser trochanter, sub-trochanter and femur mid-shaft levels.

Asterisk denotes statistically significant difference $(p<0.05)$ compared to non-athletes. When significant, values in athletes are greater compared to non-athletes, except in case of swimmers, where values are smaller compared to non-athletes. HJ - high-jump, TJ - triple-jump, SC - soccer, SQ - squash, $\mathrm{PL}$ - power-lifting, ER - endurance running, SW - swimming, NA - non-athletes

Figure $2 b$. Estimated marginal means with $95 \%$ confidence intervals for $I_{\min }$ and $I_{\max }$ at lesser trochanter, sub-trochanter and femur mid-shaft levels.

Asterisk denotes statistically significant difference $(p<0.05)$ compared to non-athletes. When significant, values in athletes are greater compared to non-athletes, except in case of swimmers, where values are smaller compared to non-athletes. HJ - high-jump, TJ - triple-jump, SC - soccer, SQ - squash, PL - power-lifting, ER - endurance running, SW - swimming, NA - non-athletes 